\title{
AS UNIDADES DE CONSERVAÇÃO NA PERSPECTIVA DA EDUCAÇÃO AMBIENTAL
}

\author{
Camila Aparecida da Cruz ${ }^{1}$; Fernanda Sola ${ }^{2}$
}

\section{RESUMO}

A educação ambiental é referenciada pelo Sistema Nacional de Unidades de Conservação como uma ferramenta importante para a criação, manutenção e valorização desses locais. Já a PNEA prevê que essa deverá ser uma prática recorrente e acessível a toda população. O entendimento de como ocorre a intersecção desses dois assuntos é o produto deste artigo. Para embasar as discussões, além das referências legais e científicas, utilizaram-se, também, as Diretrizes para a Estratégia Nacional de Comunicação e Educação Ambiental em Unidades de Conservação, que pretende nortear as ações de educação ambiental nesses espaços. Espera-se, assim, com a tessitura desse estudo teórico projetar os aspectos que favoreçam as ações de educação ambiental em unidades de conservação, além de incitar uma reflexão sobre a real função dessas áreas.

Palavras-chave: educação ambiental, unidade de conservação, reflexão.

\begin{abstract}
Environmental education is referenced by the SNUC as an important tool for creating, conservation and enhancing these locations. Already the PNEA predict this should be a recurring practice and accessible to the whole population. Understanding how the intersection of these two issues happens is the product of this article. To support the discussions, in addition to legal and scientific references, it was used also the Guidelines for the National Strategy for Communication and Environmental Education in Protected Areas, which aims to guide the actions of environmental education in these areas. It is hoped, thus, whit this theoretical study to project the aspects that favor the actions of environmental education in conservation units as well as inciting a reflection on the real function of these areas.
\end{abstract}

Keywords: environmental education, conservation unit, reflection.

\section{INTRODUÇÃO}

Muitas são as variáveis relacionadas com as questões ambientais que afligem a sociedade mundial. O modelo de crescimento adotado, a visão antropocêntrica que coloca o ser humano como um ser superior aos demais elementos da natureza, a recorrente materialização do capitalismo em bens de consumo, todas essas formas de pensar e agir vêm causando sérios problemas ao equilíbrio da relação sociedade e ambiente. Para Carvalho (1998) essas consequências também se apresentam como resultado do dualismo que tem dominado o pensamento moderno, fragmentando e

\footnotetext{
${ }^{1}$ Universidade Federal de São Carlos. E-mail: camilaac.ferreira@ hotmail.com

${ }^{2}$ Universidade Federal de São Carlos. E-mail: sollafernanda@gmail.com
} 
dividindo em polos contrários conhecimentos que deveriam ser compreendidos de forma integral. Para Charlot e Silva (2005) apesar de ser uma realidade esse pensamento dicotômico entre homem, natureza e cultura, essa é uma prática equivocada, já que o entendimento de como ocorrem as relações do homem com a natureza é, também, uma forma de compreender as interações sociais.

Assim, perceber a emergente necessidade de se repensar as relações sociais e ambientais é uma etapa indispensável ao se falar de sustentabilidade. Passos fundamentais também nessa discussão são o questionamento e a superação da visão centralizada no homem, como ser imponente, apartado da natureza e com poderes para dominá-la e dela fazer uma mera fornecedora de recursos, transcender esse pensamento é essencial para se ultrapassar a crise civilizatória ${ }^{3}$ (LEFF, 2012).

Nesse contexto Carvalho (1998) vincula a degradação ambiental, o capitalismo desenfreado e os modos sociais como centro de uma grande crise, que centraliza suas raízes na maneira como o ser humano se relaciona com natureza. Quintas (2009) também defende que a crise ambiental é a crise da própria sociedade e que

[...] os danos e riscos ambientais decorrem de uma determinada ordem social, que se constituiu, historicamente, e se mantém por meio de relações de dominação seja da natureza por seres humanos, seja de humanos por outros humanos. (QUINTAS, 2009, p. 37).

Sorrentino (2011) lembra que é necessário um compromisso de todos para a superação do modelo de desenvolvimento vigente, compromisso esse que exige participação, pertencimento, comprometimento, pluralidade de olhares e diálogos. É neste sentido que as políticas públicas em educação ambiental se fazem indispensáveis, fomentando, valorizando e interligando atividades locais a demandas globais. Portanto, assim como destacado na Conferência Intergovernamental de Tbilisi a educação ambiental deve proporcionar aos seus participantes um processo gradativo de desvelamento, com a finalidade de que os valores, os conceitos e o desenvolvimento de habilidades possam propiciar uma nova forma de se estabelecer as relações entre os seres humanos, a natureza e sua pluralidade cultural.

Nessa perspectiva as unidades de conservação, além da proteção da biodiversidade, devem ser constituídas como locais que possuem um importante papel

\footnotetext{
${ }^{3}$ Ao utilizar o termo crise civilizatória Leff (2012) justamente chama a atenção para a ampliação do entendimento das questões ambientais. Não limitando essas questões a saberes ecológicos ou simplesmente à ausência de conhecimento e tecnologias. Ao se falar da crise ambiental fala-se, obrigatoriamente, da distorção dos valores éticos que tem guiado o ser humano.
} 
na construção da relação homem-natureza. Para o Ministério do Meio Ambiente as unidades de conservação apresentam-se como importantes ferramentas na manutenção dos recursos naturais, que em longo prazo têm um papel fundamental na garantia da biodiversidade e perpetuação da qualidade de vida.

No Brasil as unidades de conservação são áreas naturais demarcadas e criadas pelo Poder Público com a finalidade de proteger e conservar a biodiversidade, as características culturais das populações tradicionais oriundas desses locais e seus patrimônios históricos e culturais. (SNUC, 2000). De acordo com a legislação brasileira essas unidades podem ser classificadas em dois grandes grupos: as de proteção integral e as de uso sustentável, totalizando, doze categorias de manejo em seu conjunto. A gestão desses espaços poderá ser de responsabilidade da União, dos estados, dos municípios ou ainda de particulares.

O Sistema Nacional de Unidades de Conservação da Natureza, instituído pela Lei 9.985 de 18 de julho de 2000, prevê que as unidades de conservação de proteção integral compõem áreas com maiores restrições, seu principal objetivo é assegurar a integridade dos ecossistemas presentes nessas áreas e o desenvolvimento da pesquisa científica. Em tais locais a visitação é apenas permitida se a finalidade for educativa. Pertencem a esse grupo as seguintes categorias de manejo: Estação Ecológica, Reserva Biológica, Parque Nacional, Monumento Natural e Refúgio da Vida Silvestre.

Já como principal característica das unidades de uso sustentável pode-se citar a exploração sustentável das florestas nativas integrada à pesquisa científica. Outra característica importante desse grupo é a admissão da permanência de populações tradicionais no interior dos seus limites. Compõe esse grupo a Área de Proteção Ambiental, Área de Relevante Interesse Ecológico, Floresta Nacional, Reserva Extrativista, Reserva de Fauna, Reserva de Desenvolvimento Sustentável e Reserva Particular do Patrimônio Natural.

Algumas estratégias possíveis para o desenvolvimento da educação ambiental nesses espaços seriam os cursos desenvolvidos para os professores, funcionários da unidade e outros grupos organizados, além da produção de materiais didáticos e programas que envolvessem as comunidades do seu entorno. (CERVANTES, et. al., 1992, p. 1077). Entende-se, consequentemente, que as atividades de educação ambiental desenvolvidas em unidades de conservação devem propiciar uma transgressão, uma 
ampliação dos conhecimentos e da forma de visualizar e entender as relações ambientais. Deste modo, a educação ambiental apresenta-se como imensa possibilidade para viabilizar o uso público em unidades de conservação.

\section{CONSTRUÇÃO HISTÓRICA DO CONCEITO DE EDUCAÇÃO AMBIENTAL}

Para conceber o enlace entre a educação ambiental e as áreas protegidas é interessante apresentar uma construção histórica do próprio conceito de educação ambiental. Entender quais foram suas bases e como suas concepções podem interferir nesses espaços é de suma importância para a sequência dessa discussão.

\section{O Conceito de Educação Ambiental}

O conceito de educação ambiental foi se formando com base nas recorrentes discussões e objetivos pretendidos para as práticas que envolvessem o tema. Assim como ocorre com outros termos, ao se conceituar a educação ambiental espera-se sintetizar em um amontoado de palavras os anseios, os desejos e as concepções que envolvem todo o movimento de ação e reflexão que é a própria educação ambiental.

No Brasil a conceituação legal da educação ambiental é fornecida pela Política Nacional de Educação Ambiental, fica evidente, que a construção do conceito de educação ambiental apresentada nessa legislação foi fortemente baseada na descrição feita durante o Congresso de Belgrado. O documento denominado Carta de Belgrado demonstra a necessidade de sensibilizar, mas também a necessidade de desenvolver competências e habilidades para se resolver os problemas relacionados ao meio ambiente, destaca, sobretudo, a necessária atuação preventiva da educação ambiental. É importante ressaltar, que a questão central da Carta de Belgrado é o processo que envolve a educação ambiental e a obrigatoriedade desses processos de criarem novos olhares sob os problemas ambientais.

Assim, o primeiro passo na busca da compreensão da educação ambiental brasileira é na direção de suas raízes. Entender o modo como sua semente foi plantada é fundamental, Guimarães (2012) recorda que o processo embasador da sociedade atual traz consigo uma divisão social, uma hierarquização, uma visão onde residem opressores e oprimidos, enfatiza que essa relação de superioridade também reflete a forma como os indivíduos entendem a natureza como algo apartado do meio social, 
facilitando dessa forma o poder de dominação da natureza pela sociedade. E foi como resposta a essa dominação que a partir da década de 1960 viu-se borbulhar aos arredores do mundo diversos documentos que faziam referência a uma iminente crise ambiental que poderia frear o desenvolvimento na Terra ou ainda colocar em risco a permanência humana no planeta. Desta maneira, a educação ambiental entra na pauta mundial como resposta necessária aos anseios daqueles que pretendiam reverter tal cenário.

Foi ao decorrer da década de 1970 que a educação ambiental começou a se instaurar no Brasil como reflexo das ações ocorridas ao redor do mundo, mas principalmente, por forte pressão internacional. É válido lembrar que nesse período o país vivenciava uma política desenvolvimentista que buscava alavancar a economia a qualquer custo. Lima (2011) afirma que a educação ambiental começa a dar os seus primeiros passos em terras brasileiras por intermédio dos órgãos estatais, assim, considerando as ideologias defendidas por tais estabelecimentos, pode-se concluir que a educação ambiental trabalhada inicialmente no Brasil era "subordinada a uma orientação maior do governo, que tinha um perfil desenvolvimentista, tecnocrático e autoritário e que demarcava claramente os limites do que era possível avançar nessa área”. (LIMA, 2011, p. 144).

Dias (2004) reforça a ideia de que esse processo de interiorização das práticas que envolviam a educação ambiental tanto no Brasil, como em vários países do mundo se deu principalmente por órgãos ambientais, e pouco foi difundida no interior das instituições educacionais, recorda, ainda, que o seu caráter transformador foi rapidamente podado em seus primeiros anos, já que não era de interesse da ordem política e econômica a criação de uma nova visão sobre as relações sociais, humanas e ambientais.

Com o seu início regido pelo autoritarismo personificado pelo regime militar, a educação ambiental brasileira, apesar de algumas exceções, centralizou os seus trabalhos em ações que não gerassem questionamentos e objetivavam apenas a adoção de comportamentos que favorecessem a conservação da natureza. Assim, a vertente conservacionista ganhou espaço e força nos debates nacionais e ainda hoje se faz presente em muitos projetos e programas.

A educação ambiental dita conservacionista vislumbra os problemas ambientais considerando apenas os seus aspectos ecológicos. Nesse entendimento as questões 
ambientais são reduzidas à falta de conhecimento sobre o funcionamento dos ecossistemas, aqui, não há espaço para uma visão ampliada, onde o ambiente social também é considerado, assim, os argumentos que colocam a poluição e a degradação ambiental como efeitos colaterais necessários à manutenção da qualidade de vida na Terra são comumente ouvidos. Outro aspecto interessante que reflete as crenças de uma educação ambiental conservacionista é o fato de os problemas ambientais sempre serem atribuídos a um ser abstrato, sem a indicação clara das responsabilidades de cada indivíduo, prevalecendo termos genéricos e reducionistas. Desta forma, como produto dos ideais conservacionistas tem-se ações que visam apenas condicionar os seus participantes a apresentarem atitudes de proteção ambiental, sem estabelecer uma reflexão ou um entendimento para além do próprio problema (LIMA, 2011).

Carvalho (1998) descreve a educação ambiental como sendo "herdeira dos dilemas políticos contemporâneos e filha direta do debate ecológico” (p.23), posicionase, ainda, contrária às práticas centradas apenas na conservação ecológica ou nas mudanças comportamentais, para tal autora a educação ambiental deve formar sujeitos que percebam o meio em qual estão inseridos e resultar em ações voltadas à cidadania, à ética e a transformação do modelo atual de concepção das relações entre os indivíduos e entre sociedade e natureza.

Sobre as alterações elencadas por Carvalho (1998) nos entendimentos das relações humanas, Layrargues (2009) enfatiza a urgência da natureza não ser mais vista, apenas, como uma fornecedora inesgotável de recursos, que é reduzida a sua utilidade e capacidade de oferecer produtos e desenvolvimento econômico.

Assim, palavras e expressões como solidariedade, participação social, engajamento, envolvimento, valorização cultural, respeito e complexidade são incorporados às discussões sobre a educação ambiental. Contrária às práticas conservacionistas, reformistas ou comportamentalistas um novo ramo que pretende a reflexão profunda das questões ambientais e que entende as questões sociais como um eixo central em suas discussões se formou. Junto a esse pensar, outras adjetivações passaram a acompanhar a expressão educação ambiental.

Espera-se, consequentemente, que esta seja uma prática educativa que contenha os preceitos críticos, emancipatórios e transformadores. Direcionando os seus esforços para o desenvolvimento de atividades que causem a reflexão, que não tenham como 
base a repetição de comportamentos isolados. Essas práticas devem favorecer um novo entendimento da natureza, onde o mito separatista entre homem e natureza é rompido. É parte essencial desse processo, para Carvalho (1998), a leitura das relações sociais e naturais, compreendendo-se assim a complexidade das questões ambientais. Quintas (2009) levanta, ainda, a necessidade de ações coletivas e organizadas que tenham as suas bases em situações concretas.

A respeito da necessidade de experiências concretas, Pernambuco e Silva (2006) recordam que o trabalho de Paulo Freire foi todo embasado nesse preceito. Suas ações sempre partiam de atividades concretas que uniam ação e reflexão, e que permitiam aos seus envolvidos a ampliação de seus horizontes, fazendo-os sujeitos do processo educativo.

Sendo assim, as práticas envolvendo a educação ambiental devem promover o pensamento crítico, capaz de ampliar o repertório de mundo do indivíduo, fazendo-o compreender o meio em que está inserido e quais são as suas relações com o padrão civilizatório atual. Novamente, enfatiza-se a necessidade e urgência em se criar novas formas de relacionamentos entre a sociedade e natureza. Sendo assim, para se alcançar os preceitos de uma educação ambiental crítica, obrigatoriamente, suas ações devem promover questionamentos que enfoquem outras dimensões, além da ecológica. Portanto, é imprescindível que seja superada a visão reducionista envolvendo as questões ambientais, desvencilhando-se, assim, do mito romântico, onde a educação ambiental tudo pode e tudo solucionará. (LOUREIRO, 2011).

Para Carvalho (2006) o poder eficaz dos processos educativos é sempre evocado como meio para se transformar a realidade atual, mas assim como Loureiro (2011), também alerta para os perigos em supervalorizar essas contribuições criando, assim, um ideário distorcido do poder da educação.

Logo, a relevância das questões sociais, políticas e econômicas juntamente com o aspecto ecológico é uma das premissas da educação ambiental. Esse fato é recordado por Dias (2004) ao retomar as recomendações estabelecidas durante a Conferência Intergovernamental de Tbilisi, fundamentalmente a recomendação número 2, que prevê o entendimento da importância da interdependência desses aspectos. Assim discussões que englobem a (in)justiça social, o acesso à educação, moradia e saúde, a fome, a violência, o acesso desigual aos benefícios ambientais, bem como seus impactos devem 
se relacionar diretamente com a educação ambiental, compondo um todo e fomentando o processo de participação das comunidades. Desta forma, gerou-se um dos princípios básicos da educação ambiental: "Considerar o meio ambiente em sua totalidade, isto é, em seus aspectos naturais e criados pelo homem" (TBILISI, 1977). Dias (2004) ainda relembra que esse princípio tem sua origem durante a conferência de Estocolmo, que formalizou a necessidade de uma abordagem integral da questão ambiental.

No entanto, Layrargues (2009) afirma que ainda hoje, mesmo apesar dos princípios estabelecidos em Tbilisi apontarem para uma educação ambiental que considerasse a amplitude das questões ambientais, o adjetivo "ambiental" que compõe a expressão educação ambiental é entendido como sinônimo de "ecológico", o que acaba dificultando a associação das questões ambientais com as questões sociais. Contudo, não se deve esquecer que "a educação ambiental é educação e, como tal, serve ou para manter ou mudar a realidade, reproduzir ou transformar a sociedade." (LAYRARGYES, 2009, p. 28).

A afirmação acima exposta vai ao encontro das concepções que Severino (2001) apresenta, ao defender que todo ato educativo tem dois caminhos a serem seguidos. $\mathrm{O}$ primeiro, aquele que é também o mais curto e até mais confortável é o caminho que nos leva a uma reprodução de comportamentos, nele uma ideologia já consolidada é apenas divulgada, é reproduzida. Já o segundo caminho nos arrasta para a possibilidade da transformação, há, aqui, uma contra-ideologia, ou seja, tudo aquilo que é dado como certo, pode ser questionado. O compromisso nesse trajeto é gerar uma capacidade de empoderamento capaz de fazer brotar novas concepções e novos entendimentos acerca das relações humanas e ambientais.

\section{Correntes, Vertentes e Outras Designações}

Lima (2011) defende que é importante estabelecer uma diferenciação entre os tipos de práticas existentes na educação ambiental, já que a partir dessa diferenciação é possível apontar seus possíveis rumos. Contudo, como evidencia Carvalho (2004) há uma dificuldade em se classificar a educação ambiental, já que os seus traçados não são claros e seus trajetos são formados por uma variada quantidade de práticas e metodologias. 
Mas apesar dessa dificuldade, Lima (2011), considerando a ausência de neutralidade do ato educativo, bem como os valores envolvidos, as ideologias e interesses, esclarece que a educação ambiental pode de uma forma mais geral transitar por dois grandes polos, onde o primeiro é representado pelo conservadorismo e o segundo pela emancipação.

Esses dois polos se relacionam com um conjunto de circunstância, atores e crenças. Em uma ponta aqueles que defendem o conservadorismo defendem o conhecimento ecológico como princípio norteador de suas concepções, em outro extremo aqueles que também consideram necessários, além desses conhecimentos, entender como as dimensões sociais, culturais, históricas e política se relacionam com as questões ambientais. (LAYARGUES, LIMA, 2011, p.6).

Educação ambiental crítica, emancipatória e transformadora são alguns exemplos, onde o principal ponto de encontro dessas vertentes é a necessidade da reconstrução da forma como o ser humano enxerga a natureza e as relações sociais. Dessa maneira o ato pedagógico de acordo com essa concepção deverá tornar o seu participante apto a perceber a reflexão, a temporalidade, a intencionalidade e a transcendência que envolvem a prática da educação ambiental. Ao se falar em reflexão, espera-se que o sujeito seja capaz de analisar, de pensar criticamente as causas e consequência de certa condição ambiental. Já a temporalidade relaciona-se com a capacidade de contextualizar essa condição ambiental dentro de um processo histórico. A intencionalidade diz respeito à capacidade de transformar ou perpetuar tal condição ambiental. Por sua vez a transcendência é a visão dessa situação diante do futuro. (QUINTAS, 2009)

Quintas (2009) resume as diferenças entre as concepções reformista, também dita conservadora por Guimarães (2004), e a transformadora, chamada de crítica por Lima (2011), considerando a forma como essas práticas entendem a sociedade e os problemas ambientais, o entendimento sobre a crise ambiental, as resoluções dos problemas ambientais e suas práticas pedagógicas. É importante destacar que a educação ambiental crítica não é uma evolução da educação ambiental conservadora, sendo que nunca existiu um momento em que a vertente conservadora evoluiu e se tornou crítica, pelo contrário a educação ambiental crítica nasce em resposta, em 
ISSN- 1413-8638

E-ISSN - 2238-5533

v. 22, n. 2, p. 208-227, 2017

oposição às concepções da educação ambiental dita conservadora (GUIMARAES, 2004).

\section{O CAMINHO DAS UNIDADES DE CONSERVAÇÃO NO BRASIL}

O termo unidade de conservação é atualmente definido pelo Sistema Nacional de Unidades de Conservação como um "espaço territorial legalmente instituído e com objetivos de conservação”. (SNUC, 2000)

Além dessa definição geral, são apresentados no corpo da lei dois grandes grupos de manejo: as unidades de conservação de uso sustentável e as unidades de conservação consideradas como de proteção integral. Esses dois grupos se diferem a partir dos seus objetivos e permissões relacionados ao manejo da área, visitação, pesquisa científica e atividades de educação ambiental. No total o Sistema Nacional de Unidades de Conservação apresenta doze categorias, cinco de proteção integral e sete de uso sustentável.

Contudo, é importante lembrar que muitas dessas categorias já existiam muito antes da publicação dessa lei, Medeiros (2006) ressalta que em 1934 já estavam previstas no Código Florestal e Código de Caça e Pesca as seguintes categorias de manejo: Parque Nacional, Floresta Nacional, Reserva de Proteção Biológica ou Estética, Parque de Reserva, Refúgio e Criação de animais Silvestres. Com a criação do Sistema Nacional de Unidades de Conservação essas denominações foram centralizadas em um único documento.

O Sistema Nacional de Unidades de Conservação da Natureza, apesar de representar um grande avanço no diálogo, sistematização de informações e procedimentos sobre as unidades de conservação brasileiras, passou a vigorar há apenas duas décadas, é necessário, assim, contextualizar como se deu a abordagem jurídica desses espaços até então.

Wainer (1999) elenca o Regimento do Pau-Brasil, lei instituída durante o Brasil Colônia no ano de 1605 que estabelecia a necessidade de autorização prévia para o corte dessa árvore, como a primeira legislação nacional a apresentar uma preocupação com a conservação florestal. Além do Regimento do Pau-Brasil, podem ser destacados outros documentos e eventos que indicavam alguma preocupação ambiental, como exemplo podem ser citados: a Carta Régia (1797), o Regimento de Cortes de Madeira (1799) e a 
Criação do Jardim Botânico do Rio de Janeiro: Importante instituição destinada à pesquisa e atividades educacionais (1808).

Contudo é importante ressaltar, que "boa parte destas medidas medias advinha dos diversos inventários realizados a serviço da coroa cora portuguesa visando determinar a existência de recursos naturais estratégicos que poderiam ser explorados e controlados." (MEDEIROS, 2006, p. 43), o que indica que a preocupação ambiental naquele momento era puramente recursista e baseada no valor econômico.

No período após a independência do Brasil, principalmente aquele posterior à proclamação da república, Medeiros (2006) destaca a criação do Código Florestal; Código de Águas; Código de Caça e Pesca; Decreto de Proteção aos Animais. (1934), do Novo Código Florestal (1965), da Lei de Proteção aos animais (1967), da Convenção do Patrimônio Mundial (1972), Estatuto do Índio (1973), da Lei da criação das Estações Ecológicas (1981), do Decreto de criação das Reservas Ecológicas (1984) e da Lei de criação das Reservas Particulares do Patrimônio Nacional (1996) como os principais instrumentos legais anteriores ao Sistema Nacional de Unidades de Conservação.

Assim como ocorreu com vários países ao redor do mundo, o Brasil também foi fortemente influenciado pela iniciativa americana ${ }^{4}$ na criação de unidades de conservação, mas, segundo Medeiros (2006) essa influência apenas se efetivou em 1937, mais de meio século após a fundação do primeiro parque estadunidense. Por isso, o ano de 1937 pode ser considerado um ano simbólico, já que é marcado pela instituição da primeira unidade de conservação brasileira, com o estabelecimento do Parque Nacional de Itatiaia nos limites entre os estados de Minas Gerais e Rio de Janeiro, contando na época com um espaço territorial de apenas 11.943 hectares $^{5}$, a sua criação foi fortemente inspirada nos preceitos americanos, contudo anterior a essa data já havia existido tentativas em se estabelecer outras duas áreas de preservação. O Atlas das Unidades de Conservação Ambiental do Estado de São Paulo (1996), ao traçar o histórico dessas áreas agrupa o trajeto brasileiro em quatro pontos distintos:

$\mathbf{1}^{\text {a }}$ fase: Com início em 1934 e seguindo até a década de 1960 esse período foi marcado pela ideia de se preservar áreas com valores científicos e estéticos. A ideologia das

\footnotetext{
${ }^{4}$ A criação do Parque Yellowstone nos Estados Unidos em $1^{\circ}$ de março de 1872 é um importante marco na instituição de áreas naturais protegidas.

${ }^{5}$ Em 1982 a área do Parque Nacional de Itatiaia foi ampliada para 28.084 hectares.
} 
unidades de conservação vistas como espaços intocáveis tem sua influência situada nesse período.

$2^{\text {a }}$ fase: As décadas de 1960 e 1970 foram marcadas pela criação de unidades de conservação que pudessem contribuir para manutenção da vida de espécies ameaçadas de extinção.

$\mathbf{3}^{\mathbf{a}}$ fase: Foi na década de 1980 que os ideários a respeito da diversidade genética foram agregados às áreas protegidas.

$4^{\text {a }}$ fase: A partir de 1990 incluem-se nas discussões sobre unidades de conservação os aspectos sociais e culturais, além da necessidade de visualizar esses espaços sobre a ótica da sustentabilidade.

Atualmente, de acordo com o Cadastro Nacional de Unidades de Conservação, plataforma criada e mantida pelo Ministério do Meio Ambiente, o Brasil conta com um total de 1979 unidades, divididas entre aquelas de proteção integral e as de uso sustentável. Sendo que desse total $69 \%$ pertencem ao grupo de uso sustentável e apenas $31 \%$ compõem as unidades de proteção integral. A Tabela 1 sintetiza essa divisão por esferas e por categorias de manejo.

Tabela 1 - Unidades de conservação de proteção integral - Fevereiro de $2016^{6}$

Esfera

\begin{tabular}{|c|c|c|c|c|c|c|c|c|}
\hline \multirow[b]{2}{*}{ Proteção integral } & \multicolumn{2}{|c|}{ Federal } & \multicolumn{2}{|c|}{ Estadual } & \multicolumn{2}{|c|}{ Municipal } & \multicolumn{2}{|r|}{ Total } \\
\hline & $\mathrm{N}^{\circ}$ & $\begin{array}{c}\text { Área } \\
\left(\mathrm{Km}^{2}\right)^{7}\end{array}$ & $\mathrm{~N}^{\circ}$ & Área $\left(\mathrm{Km}^{2}\right)$ & $\mathrm{N}^{\circ}$ & $\begin{array}{c}\text { Área } \\
\left(\mathrm{Km}^{2}\right)\end{array}$ & $\mathrm{N}^{\circ}$ & Área $\left(\mathrm{Km}^{2}\right)$ \\
\hline Estação Ecológica & 32 & 74.681 & 59 & 47.495 & 1 & 9 & 92 & 122.185 \\
\hline Monumento Natural & 3 & 443 & 28 & 892 & 11 & 73 & 42 & 1.407 \\
\hline Parque & 71 & 253.183 & 195 & 94,816 & 113 & 383 & 379 & 348.383 \\
\hline Refugio da Vida Silvestre & 7 & 2.017 & 26 & 1.731 & 2 & 22 & 35 & 3.770 \\
\hline Reserva Biológica & 30 & 39.037 & 23 & 13.447 & 8 & 51 & 61 & 52.534 \\
\hline Proteção integral & 143 & 369.361 & 331 & 158.380 & 135 & 537 & 609 & 528.278 \\
\hline
\end{tabular}

Fonte: Adaptada pela autora da tabela de dados consolidados das unidades de conservação. http://www.mma.gov.br/areas-protegidas/cadastro-nacional-de-ucs/dados-consolidados

\footnotetext{
${ }^{6}$ A última atualização dos dados consolidados do Cadastro Nacional de Unidade de Conservação ocorreu em 26/02/2016.

${ }^{7}$ Os valores das áreas de cada categoria apresentam-se em km², contudo usualmente é apresentado em ha, a proporção entre as duas unidades de área é a seguinte: $1 \mathrm{~km}^{2}=100$ ha.
} 


\section{CONJUNÇÃO DE IDEIAS: A EDUCAÇÃO AMBIENTAL NAS UNIDADES DE CONSERVAÇÃO}

Se no cenário mundial os eventos que marcaram a trajetória da educação ambiental ocorreram ainda durante os anos de 1970 com a Conferência Mundial sobre Meio Ambiente e Desenvolvimento, em 1972, e com a Conferência Intergovernamental sobre Educação Ambiental, em 1977, no Brasil as décadas de 1980 e 1990 registraram alguns dos principais momentos envolvendo as questões ambientais e a educação ambiental. Dentre esses acontecimentos, Saito (2012) afirma que a instituição da Política Nacional do Meio Ambiente e o Sistema Nacional do Meio Ambiente, e principalmente, a promulgação da Constituição Federal representaram importantes avanços nas discussões sobre tema, bem como o estabelecimento da Política Nacional de Educação Ambiental, ao final dos anos 1990.

No âmbito legal a Política Nacional de Educação Ambiental estabelece que essa deverá ser uma prática que envolva a sociedade como um todo, em uma permanente busca pela formação de valores, vinculação entre a ética, a educação, o trabalho e as práticas sociais, além do reconhecimento e o respeito à pluralidade e à diversidade individual e cultural (BRASIL, 1999). A Política Nacional de Educação Ambiental associa, ainda, a necessidade da educação ambiental à proteção das unidades de conservação ao esclarecer que o Poder Público, em todos os níveis, deverá estimular a "sensibilização da sociedade para a importância das unidades de conservação". Por outro lado, reforçando o que prevê tal política, o Sistema Nacional de Unidades de Conservação enfatiza que a participação efetiva das populações locais, indispensável, durante a criação, implantação ou gestão dessas áreas, apenas ocorrerá realmente, se facilitada por processos educativos. Percebe-se, assim, o anseio dessas duas bases legais para que a educação ambiental seja verdadeiramente um instrumento em prol à gestão pública das unidades de conservação. (BRASIL, 1999; 2000)

Diegues (2005) evidencia a biodiversidade como um produto do meio cultural e do meio natural, desta forma ao se falar em conservação da biodiversidade, não se fala apenas na perpetuação das espécies, consideram-se, também, as características sociais e culturais das populações. Passos e Sato (2012) evidenciam a dificuldade, muitas vezes encontrada, em se compreender a diversidade cultural como um desafio constante nos diálogos envolvendo as questões ambientais. 
Entretanto, acerca da junção dos temas educação ambiental e unidade de conservação Quintas (2009) alerta sobre a importância de se entender qual é a concepção, qual é o entendimento acerca desses dois assuntos por parte da equipe que atuará nessas temáticas, já que essas definições estão intimamente ligadas com o resultado esperado. Por exemplo, se a unidade de conservação ainda for entendida como um santuário em que a natureza é intocada e que é protegida como uma reserva de recursos naturais necessários para se fazer girar a engrenagem da hegemonia vigente (DIEGUES, 2004), certamente a educação ambiental utilizada nesse espaço será a conservacionista e desta maneira, não haverá transformação alguma, ocorrerá, apenas, a reprodução e sistematização de conceitos já internalizados. Assim pode-se considerar um grande equívoco.

Portanto, considerar a educação ambiental em unidades de conservação através do desvelamento dos conflitos e do entendimento que natureza, cultura e o meio social são indissociáveis é condição essencial para o desenvolvimento de uma prática educativa que tenha por base uma educação emancipatória (IBASE, 2006).

\section{O que diz a ENCEA?}

Criada a partir de uma ação conjunta entre os departamentos de Educação Ambiental e Áreas Protegidas do Ministério do Meio Ambiente em parceria com o Instituto Chico Mendes de Conservação da Biodiversidade a Estratégia Nacional de Comunicação e Educação Ambiental em Unidades de Conservação (ENCEA) apresenta-se como um importante instrumento norteador das práticas envolvendo a educação ambiental em unidades de conservação. O documento foi desenvolvimento considerando aspectos inerentes aos princípios e bases da comunicação e educação ambiental, além de aspectos que visam à conservação biológica, por meio de consultas públicas e participação dos governos federal, estaduais e municipais, além de membros da sociedade civil.

A base teórica utilizada como princípio para elaboração do documento conta com as publicações mais importantes no âmbito da educação ambiental e unidades de conservação: Capítulo VI da Constituição Federal; Lei no 6.938/81 que estabelece o Sistema Nacional de Meio Ambiente ; Lei $\mathrm{n}^{\circ}$ 9.895/00 e Decreto $\mathrm{n}^{\circ}$. 4.340/02 que instituem o Sistema Nacional de Unidades de Conservação; Política Nacional de 
Educação Ambiental constituída através da Lei n 9.795/99 e Decreto $n^{\circ}$ 4.281/02; Programa Nacional de Educação Ambiental; Tratado de Educação Ambiental para Sociedades Sustentáveis e Responsabilidade Global; Plano Estratégico Nacional de Áreas Protegidas estabelecido pelo Decreto $n^{\text {o }}$ 5758/06; Política Nacional de Desenvolvimento Sustentável de Povos e Comunidades Tradicionais representada pelo Decreto $n^{\circ}$ 6.040/07; Deliberações das Conferências Nacionais de Meio Ambiente; Agenda 21 Brasileira e Política Nacional de Biodiversidade e a Convenção sobre Diversidade Biológica.

De acordo com a base teórica utilizada na ENCEA, o documento apresenta como objetivos a difusão da importância das unidades de conservação, seja em sua criação, implantação ou durante a sua gestão, além de garantir que os aspectos históricos, econômicos, culturais e sociais sejam apreciados em todas as atividades educativas realizadas. Ao que tange a importância das unidades de conservação, o documento prevê a necessidade de toda a sociedade compreender o potencial de conservação da biodiversidade nesses locais, bem como a utilização desses espaços como meios transformadores, capazes de elevar a reflexão e esclarecimentos sobre o modelo de desenvolvimento vigente. Entre os diversos objetivos apresentados como específicos, dois deles merecem destaque:

Estimular a disseminação de saberes locais, resgatar e valorizar os conhecimentos tradicionais (...); Estimular o uso público sustentável e internalizar valores de corresponsabilidade na gestão e proteção das Unidades de Conservação (Brasil, 2012, p.21).

A ênfase dada a esses dois objetivos específicos é justificada, pois, remete a ideia de que as ações de educação ambiental desenvolvidas nesses espaços buscam mais que simplesmente informar sobre a urgência de proteção do meio natural. Ao renegarem o caráter prescritivo da educação ambiental, esses objetivos incluem aspectos importantíssimos, como o de pertencimento, como o entendimento de que todos são sujeitos dotados de habilidades e competências capazes de colaborarem para que a transformação aconteça e, principalmente, que essa transformação não se restrinja a delimitação geográfica da unidade de conservação, que ela seja incorporada e refletida em ações e escolhas diárias.

A internalização dos valores de corresponsabilidade na gestão dessas áreas expõe a precisão em se evidenciar as bases que mantém a sociedade atual. Carvalho (1998) alerta-nos para a tênue ligação entre as escolhas cotidianas e a degradação 
ambiental e reforça a urgência em se repensar a forma como a natureza é entendida e como o homem com ela se relaciona. Percebe-se, assim, que a organização da ENCEA direciona de forma clara os preceitos que devem embasar as atividades de educação ambiental nas unidades de conservação. Apesar de o documento não apresentar a menção à expressão educação ambiental crítica, encontram-se em seu corpo conceitos que remetem a esta ideia, já que um de seus princípios é justamente o desenvolvimento do pensamento crítico, o que reforça tal concepção.

A importância desse documento é ainda evidenciada com a recomendação $n^{\circ} 14$, de 26 de abril de 2012 do Conselho Nacional do Meio Ambiente (CONAMA) ao determinar que a ENCEA seja adotada como referência no desenvolvimento de atividades que envolvam a educação ambiental em unidades de conservação. Dessa maneira o tratamento dado à comunicação e à educação ambiental dentro das unidades de conservação, pode contribuir para o entendimento da complexidade das relações sociais, fortalecendo e articulando a conservação do seu território, além de efetivar o disposto na Constituição Federal em seu artigo 225 que estabelece o direito de todos os indivíduos a um meio ambiente equilibrado, mas que também indica a necessidade em se estabelecer níveis de responsabilidades tanto do poder público quanto da coletividade (Brasil, 2015).

\section{CONSIDERAÇÕES FINAIS}

Reflexão, ação e reflexão. Esse ciclo interminável em que pensamentos, práticas e saberes são agregados constitui-se como norteador das discussões que envolvem a educação ambiental. A educação ambiental requer rompimentos e questionamentos, mas também significa respeito aos saberes populares, ao conhecimento e às vivências locais. Constitui o entendimento da Terra como um ser vivo, que merece respeito, devoção e cuidados. Refletir sobre a educação ambiental é romper com o mito da individualidade, onde cada pessoa deve se responsabilizar por fazer a sua parte. $\mathrm{Na}$ busca por justiça social, justiça ambiental e na superação da grande crise civilizatória que assola os dias atuais, discursos individualistas precisam ser enfraquecidos. Em contrapartida ações que busquem a composição de grupos, coletivos e organizações em prol do bem comum devem ser evidenciadas e fortalecidas. 
Assim, ao se falar em educação ambiental a palavra de ordem deve ser transformação. A transformação do sujeito paciente em um sujeito ativo, capaz de exercer diariamente a cidadania, capaz de questionar o ordenamento mundial hegemônico e propor outros caminhos. Consequentemente, a educação ambiental é também um ato político e social. Por todos esses atributos as práticas da educação ambiental não se restringem a um único ambiente ou público, permeando por todos os âmbitos da sociedade, sem distinção de classe social, idade ou gênero.

É desta maneira, com esses ideais que uma educação ambiental que se proponha a servir de base para a transformação da realidade atual deve se apresentar nos programas que envolvam as unidades de conservação. É imprescindível, portanto, que esses locais não sejam mais vistos e romantizados como um espaço intocável e necessário, apenas, para a manutenção do sistema dominante. Muito menos que sejam idealizadas, exclusivamente, como áreas legalmente demarcadas para proteção dos recursos naturais, mas sim como locais capazes de transcenderem a engrenagem capitalista, colaborando para que uma nova forma de relacionamento com a natureza, com os animais e com os humanos seja estabelecida.

Esses pressupostos puderam ser verificados durante as extensas observações, conversas e participações nas vivências da Estação Ecológica de Angatuba, interessante relatar, que os objetivos expressos no plano de manejo para o programa de educação ambiental são quase que em sua totalidade voltados para a gestão da área, nesse caso, a educação ambiental seria utilizada para fortalecer a unidade de conservação e suas ações centralizadas na sensibilização da comunidade do entorno. Apesar de essa ser uma prática bastante rotineira quando se trata das ações educativas desenvolvidas nesses espaços, percebeu-se que no caso da Estação Ecológica de Angatuba, a estrutura do programa ao criar mecanismos que favoreçam uma reflexão transcendeu tais objetivos que representam um caráter mais conservacionista.

É importante esclarecer, também, que ao se pregar a necessidade das unidades de conservação serem utilizadas como espaços para o debate crítico das relações humanas e ambientais, não se está diminuindo ou negligenciando o seu caráter indispensável para a preservação da biodiversidade, deseja-se, contudo, que a demarcação geográfica não seja um fator determinante ao se falar de conservação ambiental. 
Cabe ainda o registro das condições institucionais dadas as práticas de educação ambiental, na contramão do que deveria ocorrer, a Secretaria Estadual de Meio Ambiente dissolveu no final de agosto de 2016 a Coordenadoria de Educação Ambiental do Estado de São Paulo, fora os percalços conceituais enfrentados na disseminação da educação ambiental, a dissolução da Coordenadoria evidencia graves problemas hierárquico no entendimento da problemática ambiental.

Percebe-se que há um longo e árduo caminho entre aquilo que se escreve e aquilo que se pratica, já que a educação ambiental é rotineiramente evidenciada e aclamada como um instrumento fundamental na construção de novas relações, na superação da crise socioambiental, aparecendo como item de destaque em diversos textos legais, contudo a sua aplicabilidade fica muitas vezes refém da ausência de recursos financeiros e humanos que não são disponibilizados.

Assim, é imprescindível que educação ambiental em unidades de conservação ou em quaisquer outros espaços, não seja vista apenas como um meio sensibilizador de pessoas sobre a preservação ambiental. A educação ambiental precisa ser refletida, entendida e exercitada como um canal onde os coletivos ganham voz, onde são desmistificadas as verdades ditas absolutas.

Contudo, para que isso seja realmente possível e efetivamente aconteça, as ações envolvendo a educação ambiental devem se desvencilhar das técnicas puramente prescritivas e expositivas. Em seu dia a dia, essa prática deve, necessariamente, incorporar palavras e expressões como participação, respeito, construção do conhecimento, questionamentos, pluralidade, coletividade e inclusão.

\section{REFERENCIAS}

BRASIL. Estratégia nacional de comunicação e educação ambiental. 2012. Disponível em: www.icmbio.gov.br/portal/images/stories/comunicacao/publicacao_encea.pdf. Acesso em: 20 out. 2015.

Lei $\mathbf{n}^{\circ}$ 9.795, de 27 de abril de 1999. Dispõe sobre a educação ambiental, institui a Política Nacional de Educação Ambiental e dá outras providências. DF, 1999. Disponível em: http://www.planalto.gov.br/ccivil_03/leis/L9795.htm. Acesso em: 12 set. 2015.

Lei $n^{0}$ 9.985, de 18 de julho de 2000. Institui o Sistema Nacional de Unidades de Conservação da Natureza - SNUC, e dá outras providências. DF, 2000. 
Disponível em: http://www.planalto.gov.br/ccivil_03/leis/L9985.htm. Acesso em: 12 set. 2015 .

Ministério do Meio Ambiente. Unidade de conservação e território: reconhecendo o contexto socioambiental e o geopolítico. Brasília: MMA, 2015.

Brasília: MMA, 2012.

CARVALHO, I. C. M. O mundo da vida não cabe em gavetas. In: Em direção ao mundo da vida: Interdisciplinaridade e Educação Ambiental. Brasília: Ministério do Meio Ambiente, Diretoria de Educação Ambiental, 1998. p. 7-9.

Mudando as Lentes: Repensando as relações entre sociedade, natureza e cultura. In: Em direção ao mundo da vida: Interdisciplinaridade e Educação Ambiental. Brasília: Ministério do Meio Ambiente, Diretoria de Educação Ambiental, 1998. p. 18-23.

Educação ambiental crítica: nomes e endereçamentos da educação. In: LAYRARGUES, P. P. (Coord.). Identidades da educação ambiental brasileira. Brasília: Ministério do Meio Ambiente, Diretoria de Educação Ambiental, 2004. p. 13-24.

CERVANTES, A. L. A., BERGAMASCO, A., CARDOSO, C. J., AOKY, H., MOTA, I. S., ADAMENAS, J., FONTES, M. A., ROBIM, M. J., TABANEZ, M. F., HERCUliAnI, S. Diretrizes Para os Programas de Uso Público do Instituto Florestal do Estado de São Paulo - SMA. In: Anais - $2^{\circ}$ Congresso Nacional sobre Essências Nativas. Revista do Instituto Florestal. São Paulo. v. 4. 1992. p. 1076-1080.

CHARLOT, B; SILVA, V. A. Relação da natureza com a educação ambiental. In: SATO, M; CARVALHO, I. C. M.(orgs). Educação Ambiental. Artmed, 2005. p. 6778.

DIAS, G.F. Educação Ambiental: Princípios e Práticas. 9.ed. São Paulo: Gaia, 2004. p. 101-200.

DIEGUES, A.C. $O$ Mito moderno da natureza intocada. $4^{\text {a }}$ ed. São Paulo: Hucitec/NUPAUB/USP, 2004.

Sociobiodiversidade. In: FERRARO-JUNIOR, L.A. Encontros e caminhos: formação de educadoras(es) ambientais e coletivos educadores. Brasília: MMA, 2005. Vol. 1. p. 303-3012.

GUIMARÃES, M. Educação ambiental crítica. In: LAYRARGUES, P. P. (Coord.). Identidades da educação ambiental brasileira. Brasília: Ministério do Meio Ambiente, Diretoria de Educação Ambiental, 2004. p. 25- 34.

2012. p. 9-16.

Caminhos da educação ambiental. 5.ed. Campinas: Papirus,

IBASE. Conflitos ambientais no Brasil: natureza para todos ou somente para alguns? Rio de janeiro, 1997.

LAYRARGUES, P. P. Educação ambiental com compromisso social: o desafio da superação das desigualdades. In: LOUREIRO, C.F.B; LAYRARGUES, P. P; CASTRO, R. S. (orgs). Repensar a Educação Ambiental: Um olhar crítico. São Paulo: Cortez, 2009. p. 11-32. 
LEFF, E. Saber Ambiental: sustentabilidade, racionalidade, complexidade, poder. Tradução de Lúcia Matilde Edilch Orth. Petrópolis, RJ: Vozes, 2012.

LIMA, G. L. C.Educação Ambiental no Brasil - Formação, identidades e desafios. 1.ed. Campinas: Papirus, 2011. p. 99-208.

LOUREIRO, C.F.B. Educação ambiental e movimentos sociais na construção da cidadania ecológica e planetária. In: CASTRO, R.S, et. al (orgs), Educação ambiental: repensando o espaço da cidadania. 5.ed. São Paulo: Cortez, 2011. p. 73-104.

MEDEIROS, R. Evolução das Tipologias e Categorias de Áreas Protegidas no Brasil. In: Ambiente e Sociedade. IX(1): 41-64, 2006.

PASSOS, L. A; SATO, M. Estética da Carta da Terra: pelo prazer de (na tensividade) com-viver com a diversidade! In: RUSCHEINSKY, A. Educação Ambiental: Abordagens Múltiplas: Penso, 2012. p. 17-41.

PERNANBUCO, M. M; SILVA, A. F. G. Paulo Freire: a educação e a transformação do mundo. In: CARVALHO, I. C. M; GRÜN, M; TRAJBER, R. Pensar o Ambiente: bases filosóficas para a Educação Ambiental. Ministério da Educação, Secretaria de Educação Continuada, Alfabetização e Diversidade, UNESCO, 2006. p. 207- 220.

QUINTAS, J. S. A educação no processo de gestão ambiental pública: a construção do ato pedagógico. In: LOUREIRO, C.F.B; LAYRARGUES, P. P; CASTRO, R. S. (orgs). Repensar a Educação Ambiental: Um olhar crítico. São Paulo: Cortez, 2009. p. 33-80.

SAITO, C. H. Política Nacional de Educação ambiental e Construção da Cidadania: Revendo os desafios contemporâneos. In: RUSCHEINSKY, A. Educação Ambiental: Abordagens Múltiplas: Penso, 2012. p. 54-76.

SORRENTINO, M. Desenvolvimento Sustentável e participação: algumas reflexões em voz alta. In: CASTRO,R.S, et. al (orgs), Educação ambiental: repensando o espaço da cidadania. 5.ed. São Paulo: Cortez, 2011. p. 19-26.

WAINER, A. H. Legislação Ambiental do Brasil: subsídios para a história do Direito Ambiental. Rio de Janeiro: Forense, 1999. 